\title{
Un nuevo fragmento de Pitágoras
}

\author{
RICARDO MARTÍNEZ LACY \\ Instituto de Investigaciones Filológicas/Facultad de Filosofía y Letras \\ Universidad Nacional Autónoma de México \\ lacy@servidor.unam.mx
}

Resumen: D.S. XVIII.1.1 contiene una cita de Pitágoras que no ha sido tomada en cuenta como fragmento, a pesar de que no puede haber dudas de que el autor se basaba en una obra considerada auténtica.

PALABRAS ClaVE: alma, fragmento, muerte, Pitágoras.

1. No cabe duda de que, de todos los filósofos presocráticos, el más famoso es Pitágoras de Samos; ello se debe, entre otras cosas, a que todos los alumnos de secundaria están obligados a estudiar el teorema que lleva su nombre. Es interesante hacer notar, además, que este hombre fue el primero en ser llamado amante de la sabiduría, es decir, filósofo (D.S. X.10). Sin duda, es el griego más famoso del siglo VI a.C. Esto es una consecuencia del hecho de que, desde la propia antigüedad, su pensamiento llamó mucho la atención, lo cual ha creado una situación documental compleja.

En efecto, actualmente, priva la idea de que Pitágoras no escribió nada y de que, por lo tanto, hay que buscar sus doctrinas en exponentes anteriores a Platón, quien dio un giro tal a sus ideas, que es imposible rastrearlas en la tradición posterior a él.

A continuación presento un fragmento de Pitágoras posterior a Platón y me propongo enfrentarme a la tendencia que se opone a reconocer fragmentos pitagóricos. Para ello, presentaré testimonios de que, efectivamente, Pitágoras dejó obra escrita leída antes y después de Platón.

2. Más concretamente: acerca de la conservación de la obra de Pitágoras hay dos posiciones entre los estudiosos de la filosofía antigua: la mayoritaria, representada por Zeller (y Mondolfo), Diels y Kranz, los recopiladores de los fragmentos de los presocráticos, así como por Burnet y Guthrie; y la minoritaria, defendida por Dodds, Gigon y Riedweg. ${ }^{1}$

1 Eduard Zeller, La filosofía dei greci nel suo sviluppo storico, Rodolfo Mondolfo (ed.), 5a. ed., 3 vols., La nuova Italia, Firenze, 1950 (la primera edición es de 1892; hay traducción al español publicada en Buenos Aires), I, pp. 288-685, en especial las pp. 288-385; Hermann Diels y Walther Kranz, Die Fragmente der Vorsokratiker, 6a. ed., 3 vols., Weidmann, Berlín, 
Estas diferencias reflejan una contradicción aparente entre los testimonios antiguos, como se puede comprobar fácilmente consultando las páginas 200 a 202 del primer volumen de la espléndida recopilación de Eggers y Juliá de Los filósofos presocráticos. ${ }^{2}$

Es conveniente empezar por examinar el pasaje 306, una cita que el historiador de la filosofía del siglo III d.C., Diógenes Laercio, hace del pitagórico del siglo IV a.C., Aristoxeno, que afirma: "También los demás pitagóricos decían que no todas [las doctrinas] debían comunicarse a todos [los hombres]..." (D.L. VIII.15.) ${ }^{3}$

Esto implica que las doctrinas y, en caso de haber existido, los escritos pitagóricos no sólo distaban de ser obra de difusión, sino que originalmente estaban destinados sólo a los iniciados en la escuela de Pitágoras.

Sin embargo, esto se contrapone con lo que el propio Diógenes Laercio, citando a Heráclito, contemporáneo de Pitágoras, había dicho: "Algunos insisten, en broma, en que Pitágoras no dejó ningún libro, en lo cual se equivocan. Así Heráclito, el físico, ha gritado a toda voz y ha dicho: 'Pitágoras, hijo de Mnesarco, se ejercitó en informarse más que los demás hombres, y con lo que extrajo de esos escritos formó su propia sabiduría: mucha erudición, arte de plagiarios'" (VIII.6). ${ }^{4}$

Este pasaje implica que, a pesar de las reservas enunciadas por Aristoxeno dos siglos más tarde, había libros accesibles de Pitágoras en vida de éste, ya fuera que su propio autor publicara obras para no iniciados o que alguno

1951-1952 (la primera edición data de 1903); John Burnet, Early Greek Philophy, 4a. ed., Londres, 1930; W.K.C. Guthrie, A History of Greek Philosophy, 5 vols., University Press, Cambridge, 1962-1980 (hay traducción al español publicada en Madrid por Gredos), I, pp. 146-340, particularmente las pp. 148-172; E.R. Dodds, The Greeks and the Irrational, California University Press, Berkeley, 1951 (hay traducción española publicada en Madrid por Revista de Occidente), p. 168n.; Olof Gigon, Los orígenes de la filosofía griega de Tales a Parménides, traducción de M. Carrión G., Gredos, Madrid, 1970 (la edición original apareció en Basilea en 1945), p. 138 y Christoph Riedweg, “'Pythagoras hinterliess keine einzige Schrift'-ein Irrtum? Anmerkungen zu einer alten Streitfrage", MH, LIV, 1997, pp. 65-92.

2 Conrado Eggers Lan et al. (eds.), Los filósofos presocráticos, 3 vols., Gredos, Madrid, 1978-1980.

3 Este testimonio encuentra su confirmación en otro del autor romano del siglo II d.C., Aulio Gelio (I. 9), según el cual, los discípulos de Pitágoras pasaban por tres grados: akoustikoí (oyentes), luego mathematikoí (matemáticos) y finalmente physikoí (físicos). Agradezco las referencias a Aulio Gelio a la doctora Amparo Gaos Schmidt.

4 Traducción modificada de Eggers y Juliá. Walter Burkert ("Pythagoreische Retraktationen: Von den Grenzen einer möglischen Edition", en Walter Burkert et al. (eds.), Fragmentsammlungen philosophischer Texte der Antike. Le raccolte dei frammenti di filosofi antichi. Atti del Seminario Internazionale, Ascona, Centro Stefano Franscini 22-27 settembre 1996, Gotinga, Vandenhoeck \& Ruprecht, 1998, pp. 303-319, en la p. 305) afirma que este fragmento de Heráclito es un testimonio terciario, pero no presenta argumentos. 
de sus alumnos iniciados hubiera abandonado la escuela y dejado leer esas obras a no iniciados, como pudo haber sido el caso de Heráclito. Como si esto no fuera suficiente, el testimonio heraclitiano se ve confirmado por otro del siglo V a.C., donde se afirma que: "Ión de Quíos, en los Triagmoí, dice que [Pitágoras] compuso algunos poemas y los atribuyó a Orfeo" (D.L. VIII.8). ${ }^{5}$

Esta contradicción se ve complicada por otra afirmación de Diógenes Laercio (VIII.15), quien dice que la obra de Pitágoras sólo se conoció un siglo después de su vida, en la época de Ión de Quíos, cuando fue publicada por otro pitagórico de nombre Filolao. Está claro que pudo haber habido varias ediciones de mayor o menor difusión y el que Filolao diera a conocer las doctrinas pitagóricas no obsta para que pudieran haberse conocido libros publicados en ediciones anteriores y difundidas entre un público más reducido.

Es necesario pensar, en consecuencia, que siempre hubo libros de Pitágoras publicados que circulaban más o menos ampliamente. Esto se confirma por lo tardío de la tradición contraria según la cual Pitágoras no escribió nada. En efecto, el primero en negar que Pitágoras escribiera fue Flavio Josefo, historiador y político de finales del siglo I d.C. , quien declaró: "Hay acuerdo en que no hay escrito alguno de él [esto es, de Pitágoras]" (C. Apion I. 163).

Sin duda, desde el punto de vista del valor testimonial de los tres pasajes citados, es claro que deben preferirse dos cercanos cronológicamente a Pitágoras a otro escrito originalmente siete siglos después de la vida de este filósofo.

3. En vista del estado de la documentación aquí expuesto, sorprende el tono categórico que utilizan Diels, Burnet y otros. El primero, por ejemplo, declara que "escritos de Pitágoras son inconcebibles". ${ }^{6}$ Por su parte, Burnet afirma que "Pitágoras prefirió la instrucción oral a la difusión de sus opiniones por escrito y no fue sino en los tiempos alejandrinos que alguien se aventuró a falsificar libros en su nombre". ${ }^{7}$ Para dar un último ejemplo, Jonathan Barnes, tal vez el historiador contemporáneo más prestigioso de la filosofía griega, dice con tono seguro: "Pitágoras mismo tuvo la sabiduría de no escribir nada."8

Este último autor cita a Heráclito, Ión de Quíos y Aristoxeno, pero afirma que las aseveraciones de los autores antiguos han sido refutadas por Burkert,

5 Traducción corregida de Eggers y Juliá.

6 Op. cit., n. 1, vol. I, p. 104.

7 Jhon Burnet, Early Greek Philosophy, 2a. ed., Adam and Charles Black, Londres, 1908 (la 1a. ed. es de 1892), pp. 100-101.

8 The Presocratic Philosophers, 2a. ed., Routledge, Londres, 1989, p. 100. 
sin duda el más famoso especialista contemporáneo en la religión griega. ${ }^{9}$ La afirmación siguiente sorprenderá a muchos pero lo que con tanta firmeza dice Barnes no es preciso, pues el autor citado por él sólo asegura que el hecho de que haya habido pitagóricos que le atribuyeron obras propias al fundador de su escuela impide distinguir los fragmentos auténticos de los falsos.

Hay que añadir que, a su vez, Burkert sostiene, sin mostrar el menor asomo de dudas, que todos los fragmentos atribuidos a Pitágoras en la época helenística —es decir, en los últimos tres siglos antes de Cristohan sido recopilados, ${ }^{10}$ lo cual es simplemente falso, como se verá más adelante.

En general, se puede decir que los que afirman que Pitágoras no escribió nada no sólo niegan el valor de los claros testimonios de Heráclito y Ión de Quíos, sino que se apoyan en autores que vivieron setecientos años después de lo que se supone que testimonian o aún más tarde.

En general, se puede decir de todos estos autores modernos que su tono va en contra de la complicada situación documental ya expuesta y que, por lo dicho sobre ésta, se esperarían por lo menos expresiones matizadas. ${ }^{11}$

4. En contraste con la contundencia de estas posiciones, las afirmaciones de Dodds y Gigon son incidentales y apenas en 1996, Christoph Riedweg, historiador de la filosofía suizo, las refutó con éxito en una conferencia que al año siguiente se publicó como artículo en la muy seria revista Museum Helveticum.

Para combatir la tendencia dominante de que Pitágoras no dejó nada escrito, Riedweg simplemente ha mostrado la pertinencia de Heráclito y Ión y la inferioridad de los otros testimonios. Además, este autor propone reconocer algunos fragmentos y hacer una recopilación de ellos.

A continuación empieza la parte propositiva en la que, siguiendo las conclusiones de Riedweg, presento un fragmento de Pitágoras descubierto casualmente.

En efecto, a partir de la semana santa del año en que se publicó el artículo mencionado en Museum Helveticum, decidí emprender una investigación sobre los ejércitos helenísticos. La época helenística inicia con la repentina

9 Walter Burkert, Lore and Science in Ancient Pythagoreanism, Harvard University Press, Cambridge, 1972, pp. 218-220. En el artículo citado (supra n. 4, p. 306) Burkert acepta los argumentos de Riedweg, cuyo artículo apareció después del seminario de Ascona, pero alega que, de todos modos, los textos de Pitágoras no pudieron ser filosóficos; esto no obsta para afirmar que el fragmento presentado en este artículo no fue escrito por el samio.

10 Ibid., p. 220n.

11 Una enumeración completa de los autores y obras donde se sostiene la misma posición negativa puede consultarse en Riedweg, op. cit., p. 68n. 
muerte de Alejandro Magno, la cual provocó la guerra de los sucesores o diádocos (por su nombre en griego: $\delta \iota \alpha \delta o ́ \chi o \iota)$. Sin duda la mejor fuente sobre esas guerras son los libros XVIII al XX de la compilación titulada Biblioteca histórica de Diodoro de Sicilia, historiador del siglo I a.C. y, por lo tanto, del fin de la época helenística. Pues bien, el libro XVIII empieza con las siguientes palabras:

Pitágoras de Samos y algunos otros filósofos antiguos declararon ( $\alpha \dot{\pi} \epsilon \varphi \eta \dot{\eta} \nu \alpha-$ $\tau o)^{12}$ que las almas de los hombres son inmortales; según esta opinión, ellas también conocen de antemano ( $\pi \rho \circ \nu \nu \omega \dot{\omega} \sigma \kappa \epsilon \iota \nu)$ el futuro en el momento de terminar la vida, cuando se separan del cuerpo ( $\alpha \pi \grave{o} \tau o \tilde{v} \sigma \omega ́ \mu \alpha \tau o \varsigma \chi \omega \rho \iota \sigma \mu \grave{o} \nu$ $\pi \circ \iota \dot{\omega} \nu \tau \alpha \iota)$.

Éste es el fragmento. A continuación, serán presentados algunos comentarios sobre él.

Es de notar que Diodoro hace afirmaciones muy claras y ello implica que estaba muy seguro de que Pitágoras y otros físicos declararon que el alma es inmortal y hace pronósticos al separarse del cuerpo. ${ }^{13}$ Es interesante también el uso de la palabra $\chi \omega \rho \iota \sigma \mu o ́ \varsigma$ (separación) para describir la muerte como la separación del alma y el cuerpo, porque en el Fedón (67d. 49) Platón, quien tenía fama desde la antigüedad de seguir a Pitágoras, usa la misma palabra con el mismo sentido para designar la muerte como la liberación y separación del alma con respecto del cuerpo.

En todo caso, la idea de que el alma, al separarse del cuerpo, se volvía clarividente, no es original. Ella se encuentra ya en la Ilíada donde, primero Patroclo, dirigiéndose a su matador Héctor, hace el siguiente pronóstico al morir (en traducción de Segalá y Estalella): "Tampoco tú has de vivir largo tiempo, pues la muerte y el hado cruel se te acercan y sucumbirás a manos del eximio Aquiles, descendiente de Eaco" (XVI. 852-4).

A su vez, Héctor también se vuelve previsor cuando, según el pronóstico de Patroclo, Aquiles lo mataba. Entonces el troyano profirió las siguientes, aladas palabras: "Bien te conozco y no era posible que te persuadiese, porque tienes en el pecho un corazón de hierro. Guárdate de que atraiga sobre ti la cólera de los dioses, día en que Paris y Febo Apolo te harán perecer, no obstante tu valor, en las puertas Esceas" (XXII. 356-60).

¿Sobra decir que este pronóstico también se cumplió?

12 Sigo aquí a Ian Mac Dougall, autor del léxico de Diodoro, quien traduce esta ocurrencia como "declare".

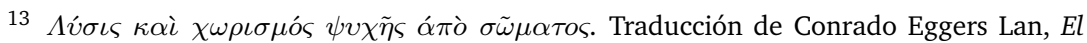
"Fedón" de Platón, Editorial Universitaria, Buenos Aires, 1971, p. 111. Agradezco al doctor Víctor Hugo Méndez Arriaga haberme señalado esta referencia. 
Pitágoras, según el pasaje citado por Diodoro, está pues siguiendo una idea de Homero que puede incluso ser anterior a éste, cosa que desde luego no se puede comprobar pues, como todos estarán de acuerdo, no hay escritos griegos anteriores a los homéricos e ideas como ésta son de difícil, si no imposible aclaración mediante la arqueología. Desde luego, sería conveniente revisar las ideas sobre el alma que prevalecían en las culturas orientales. Además, la falta de contexto impide saber si el filósofo samio tomaba la idea homérica tal cual o le daba una interpretacion filosófica o religiosa. Hay que notar que esta idea del alma que pronostica en el momento de la muerte, idea que Erwin Rohde no discute en su famoso libro Psyche, ${ }^{14}$ no es incompatible con lo que se sabe de las ideas de Pitágoras sobre la inmortalidad de las almas y su transmigración... aunque ciertamente Alejandro no necesitaba tener dones especiales de profeta para poder pronosticar que su muerte provocaría guerras entre sus generales, dado que la sucesión al trono macedónico era siempre complicada — no daba nada que desear a la de nuestra silla presidencial. A esto se añadía que Alejandro dejaba como presuntos herederos a un hermano retrasado mental y a un hijo en gestación. ${ }^{15}$

En todo caso, si es cierto lo que dice un filósofo discípulo de Platón llamado Heráclides del Ponto, citado también por Diógenes Laercio (VIII.7), Pitágoras escribió un libro Sobre el alma, es posible que el fragmento comentado provenga de ese libro.

5. Para concluir, expondré un detalle curioso que viene al caso. En la sexta edición de los fragmentos de los presocráticos, elaborada por Walther Kranz, éste, tal vez consciente de la existencia de fragmentos como el aquí presentado, agregó la palabra segura (zuverlässige) a la declaración perentoria de Diels de que "no hay una doxografía" pitagórica, con lo que quería decir que no hay un conjunto de fragmentos de Pitágoras. Pero ¿qué son lo que nosotros consideramos fragmentos, sino citas de autores antiguos que tuvieron disponibles obras atribuidas a escritores cuyas obras no han llegado o no han llegado completas al presente? ${ }^{16}$ Hay que tomar en consideración que, por su propia índole, estamos en la imposibilidad de comprobar la fiabilidad del conjunto de las citas de ninguno de los presocráticos que Diels y Kranz recogieron y, además que, como argumentó Christopher Pelling hace unos veinte años, el formato de los libros antiguos hace práctimente imposible que los escritores

14 Traducción de Wenceslao Roces, Fondo de Cultura Económica, México, 1948, reimpreso. La edición original fue publicada de 1892 a 1894.

15 Mi amiga, la médica Gabriela Enríquez, me ha hecho notar que, al momento de la muerte, se suele actuar inusualmente y decir cosas raras.

16 Esto lo repiten Burkert et al. en la obra citada en la n. 4, p. IX. 
de aquella época tuvieran frente a sus ojos más de un libro y detuvieran el papel donde lo escribían, por lo que muchas de estas citas fueron hechas originalmente de memoria y es imposible discernir cuántas, de manera que, lo que dice Burkert sobre los fragmentos pitagóricos se puede aplicar a todos los filósofos antiguos cuya obra no se ha conservado en su totalidad, o sea, a todos. En consecuencia, Pitágoras merece el tratamiento de un filósofo cuyas obras se han perdido igual que las del resto de los presocráticos y sus fragmentos deben ser reconocidos y recopilados. ${ }^{17}$

En esta colección deberá figurar el fragmento aquí presentado.

Recibido: 8 de noviembre de 2000.

17 Cfr. P.A. Brunt, "On Historical Fragments and Epitomes", CQ, XXX, 1980, p. 477-494; C.B.R. Pelling, "Plutarch's Method of Work in the Roman Lives", JHS, XCIX, 1979, pp. 74-96, en las pp. 92-93 Burkert mismo (en su cap. citado en la n. 4, p. 304) hace una severa y justa crítica de la obra de Diels y Kranz. Errónamente, cree Burkert (véase supra n. 10), que todos los fragmentos supuestamente pseudopitagóricos de la época helenística fueron recopilados por Holger Thesleff, en An Introduction to the Pythagorean Writings of the Hellenistic Period, Abo, Akademi, 1961 y en The Pythagorean Texts of the Hellenistic Period, Abo, Akademi, 1965, pero el fragmento de Diodoro presentado aquí está ausente de estos libros. Agradezco a la doctora Paola Vianello Tessaroto permitirme la consulta de estos libros. 